\title{
Rationality of Performance
}

\section{Edda Weigand}

\section{(2) OpenEdition}

\section{Journals}

\section{Electronic version}

URL: http://journals.openedition.org/philosophiascientiae/1023

DOI: 10.4000/philosophiascientiae.1023

ISSN: $1775-4283$

\section{Publisher}

Éditions Kimé

\section{Printed version}

Date of publication: 1 October 2014

Number of pages: $247-268$

ISBN: 978-2-84174-689-7

ISSN: $1281-2463$

\section{Electronic reference}

Edda Weigand, «Rationality of Performance », Philosophia Scientiæ [Online], 18-3 | 2014, Online since 19 January 2015, connection on 04 November 2020. URL : http://journals.openedition.org/ philosophiascientiae/1023 ; DOI : https://doi.org/10.4000/philosophiascientiae.1023 


\title{
Rationality of Performance
}

\author{
Edda Weigand \\ University of Münster (Germany)
}

Résumé : Ce qui semble à première vue paradoxal, « la rationalité de la performance », fait référence à une capacité extraordinaire des êtres humains, à savoir la compétence-en-performance qui leur permet d'affronter les vicissitudes de la vie et de négocier leurs buts et intérêts dans une interaction dialogique avec leurs semblables. Le concept de «rationalité de la performance » exige de passer d'une rationalité logique à une rationalité adaptative qui puisse saisir les activités changeantes et les incertitudes de la vie. Accepter ce concept suppose de changer notre mode de théorisation, d'un mode classique à un mode moderne, c'est-à-dire de passer du réductionnisme au holisme. Cet article introduit le Mixed Game Model et expose les éléments fondamentaux d'une telle théorie holistique qui place les êtres humains au centre et qui décrit leurs actions et comportements à l'aide des principes des probabilités.

\begin{abstract}
What at first sight seems paradoxical, "rationality of performance", refers to an extraordinary ability that human beings have, namely to their competence-in-performance that enables them to meet the vicissitudes of life and to negotiate their interests and purposes in dialogic interaction with their fellow beings. The concept of "rationality of performance" requires a change from a logical rationality to an adaptive rationality, which can come to grips with ever-changing activities and the uncertainties of life. To accept such a concept means changing our way of theorizing from the classical to a modern way of theorizing, i.e., moving from reductionism to holism. This paper introduces the Mixed Game Model and outlines basic elements of such a holistic theory that puts human beings at its centre and describes their actions and behaviour by means of principles of probability.
\end{abstract}




\section{The issue}

To speak of "rationality of performance" seems to be paradoxical, at least regarding the way rationality has been conceived of for ages. How could rationality in the traditional sense of logical conclusiveness be related to performance? Performance relates to so-called reality or to what is going on in life. Life is complex, reality seems to be chaotic. Nonetheless there seems to be some order in chaos, which Prigogine, though referring to biochemistry, concisely called "les lois du chaos" [Prigogine 1994]. Rationality of performance means "les lois du chaos" which human beings are obviously capable of applying when facing the challenge of life. Whereas rationality of logic means certainty, rationality of performance means tackling the uncertainties of life [Toulmin 2001]. Einstein commented on this issue with his well-known phrase:

As far as the laws of mathematics refer to reality, they are not certain; and as far as they are certain, they do not refer to reality. [Einstein 1922, 28]

In the same way as we have left behind us the certain laws of mathematics, the time has now come to leave behind us our belief in certainty and strict rationality. The traditional Western concept of rationality needs to be changed in essence, needs to become some sort of higher rationality if it is to comply with performance.

There is however a great deal of resistance among scientists to giving up the traditional concept of a theory based on strict rationality. Even if Searle opposes "the classical model of rationality", his own concept of "rationality in action" as a universal, culture-independent concept, is no less artificial as it is entirely constructed according to his rules of a competence theory of speech acts [Searle 2001]. Admittedly, there are regularities in performance but they are not the ultimate ratio. They are dominated by the overall law of performance which is a law of probability and chance. Traditional theorizing fails to do justice to the relativity of rules in performance and instead constructs its object-of-study artificially by starting from methodological exigencies. The meaning and purpose of science are in jeopardy if they are based on such artificial games. There is no way out of this dilemma other than to accept the complex as our starting point and to try to make sense of what might be the structure of complexity.

"The laws of chaos" do not mean guessing by trial and error but adapting to ever-changing surroundings. Simon proposed the term "bounded rationality" which is sometimes used in the literature [Simon 1983]. It does not seem quite adequate to me because we do not want to delimit rationality but to open it up so that it becomes capable of tackling performance. Rationality of performance is then no longer a paradox but precisely what reality demands, insofar as there is reality at all. Rationality of performance is the central component of what I called competence-in-performance, an extraordinary human ability which enables us to meet the vicissitudes of life and to negotiate 
our interests and purposes in dialogue with our fellow beings. Dialogic activities have goals and purposes. They are actions and reactions among different human beings who might have different individual purposes. Understanding cannot be presupposed. Consequently, dialogue means negotiating meaning and understanding in order to arrive at an agreement. The concept of rationality in performance requires a change from logical rationality to an adaptive rationality which can come to grips with ever-changing conditions and the uncertainty of life.

Whereas such a change in theorizing from a rule-governed, logical model to a model that allows for adaptation comes as a break in modern linguistics, the concept of adaptation has been a constitutive component in cognitive and evolutionary psychology in recent decades. For instance, Hugo Mercier \& Dan Sperber argue for rethinking the function of reasoning and suggest an adaptive concept [Mercier \& Sperber 2011]. Evolutionary psychologists, for instance, Barkow, Cosmides \& Tooby, consider the human mind as "adapted mind" [Barkow, Cosmides et al. 1992]. Psychological mechanisms which have evolved since the time of Pleistocene hunter-gatherers are considered to be adaptations created by natural selection over evolutionary time in order to face changing conditions of life.

Recently an article appeared by Hauser, Chomsky \& Fitch which demonstrates that the search for justification by evolutionary psychology and neuroscience also applies to supporters of the old Chomskyan hypotheses about language [Hauser, Chomsky et al. 2002]. The article repeats the position Chomsky took five decades ago: language is a recursive system which is innate. The only concession the Chomskyan line is prepared to make refers to the fact that language as a recursive system or "language in the narrow sense" is now conceived of as interacting with "language in the broad sense" or language as a communicative system. However, how should this "interaction" be achieved if both systems of language are defined as independent systems? Complexity is not based on the addition of independent parts but on integrated components derived from the complex whole. The article attempts to justify its artificial construction of language by the hypothesis that we are born with genes that determine a rather precise universal grammar of the recursive type. The argumentation for this rather unlikely thesis is completely based on speculation, only referring to seeming authorities, without any substantial argument or experimental proof. The authors do not hesitate to explicitly mark their assumptions as hypotheses or suggestions (see also [Weigand 2007, $29 \mathrm{ff}$ ]).

There are many other voices we might refer to in order to demonstrate that science is going to include concepts such as adaptation and open-endedness of language use in theoretical approaches. However, to accept such a concept of rationality-in-performance means changing theorizing from classical theorizing to modern theorizing, from constructing our object by methodology to deriving methodology from the complex object of performance. Physics already underwent such a change decades ago when classical physics changed 
to modern physics. What is at stake is a change from reductionism to holism if we want to describe and explain "les lois du chaos". Performance cannot be reduced to rules but includes chance and ever-changing action conditions. Human beings take account of rules as far as they go and orient themselves towards probabilities where rules come to an end. A theory of performance must therefore inevitably be based on Principles of Probability. The terms "probability" or "chaos" do not refer to statistics and measurements of calculating probability but to the common sense of human beings who know that life is a matter of probability ranging from complete unpredictability or chance to events which can be expected with rather high probability.

\section{The challenge of complexity in general}

Simon made an interesting proposal about the "architecture of complexity" in general which conforms with recent results in the neurosciences [Simon 1962]. To my mind, we are happy insofar as we are eventually able to open up the "black box" and to see, at least to some extent, how it works. The classical period of an independent philosophy is over. According to Lumsden and Wilson, it needs

intensified dialogue among the arts, humanities, and sciences of human nature. [...] A substantive familiarity with science, including especially evolutionary science, is once again de rigueur for respectable philosophy of mind. [Lumsden \& Wilson 2005, $\mathrm{xIvi]}$

Assertions about human actions and behaviour need to be justified by human nature and proved by biology and neuroscience.

The theory I have developed in recent years according to such guidelines (cf. [Weigand 2010], [Trognon 2013]) starts with goal-oriented observation [Feynman 2001]. Simple observation, i.e., restriction to the empirical level, will not suffice. We need some sort of question or scientific interest which guides our observation. By focusing on our own behaviour we can, for instance, observe that we not only take decisions by means of reasonable arguments but are also more or less affected by emotion. This interdependence of reason and emotion or "Descartes' error" has finally been proved by neurological experiments, e.g., [Damasio 1994, 2000]. Human abilities are integrated and interact with each other, which has been demonstrated, for instance, by Kendon's research on the integration of language and gesture, e.g., [Kendon 1980] or McNeill's research on the integration of thought and gesture [McNeill 2005].

The crucial feature of rationality in performance, the feature of adaptation, can be best explained by tracing it back to Gell-Mann who introduced the term "complex adaptive system" for a system which is complex and capable of changing and adapting to the environment [Gell-Mann 1994]. In this sense we 
can consider human beings as complex adaptive systems endowed with the extraordinary ability of orienting themselves in complex surroundings. Rational thinking in performance requires taking account of unpredictable events and the necessity of re-orientation. In the meantime, the concept of adaptation has become a focus of research in different disciplines and has been related to the evolution of the brain, for instance, in the collective volume on Language as a Complex Adaptive System [Ellis \& Larsen-Freeman 2010].

Other neurobiological experiments on mirror neurons have, at least to some degree, proved the observation that human beings are dialogically oriented [Rizzolatti \& Arbib 1998], [Weigand 2009a], [Iacoboni 2008]. As dialogic individuals we have to mediate between our self-interests and social concerns.

Proceeding in this way, combining goal-oriented observation with biological verification, allows us to develop theories which demonstrate that the humanities and the social sciences are interrelated with the natural sciences on the basis of the unity of knowledge or consilience. If we want to structure complexity or to find out the "laws" of chaos, we need to take account of the following basic conditions, cf. [Simon 1962]:

- The predication "complex" does not refer to linear enumeration and addition of parts but to integration and interaction of components. The whole is more than the sum of all the interactions carried out by the components.

- The starting point needs to be the complex whole.

- The components are to be derived from the whole in a complex hierarchy. Derivation means specialization or differentiation, not division into parts or arbitrarily picking out any aspect whatsoever. Integration is not achieved by the addition of parts.

- Specialization cannot be arbitrary but needs to comply with rationalityin-performance, i.e., to proceed step by step from one level to the next within the complex hierarchy. Rational specialization presupposes neardecomposability of the whole and its components. Otherwise there would be no laws of complexity. The restriction of near-decomposability draws on the basic rule of complexity which is a rule of probability. Adapting to ever-changing conditions presupposes "rational thinking" which is prepared to change direction and to include chance if necessary.

\section{$3 \quad$ Nuts and bolts of a performance theory of human action and behaviour}

Let us now draw conclusions from the general structure of complexity to a performance theory of human action and behaviour. A sine qua non will be the direction these conclusions need to take, namely from the object to 
methodology. When trying to develop a holistic approach we first need to grasp our object of study and then derive an adequate methodology from it. We should always be aware of the fact that our cognition is human cognition, not an independent ability. We are therefore unable to grasp absolute truth; we can only perceive and recognize as far as our abilities allow us to do. Developing theories by including some level of truth-conditional semantics represents an artificial construction which reduces the object to methodology and does not make sense in an advance in the complex.

\subsection{The object of study}

The first question to be posed is related to our object-of-study. How can we circumscribe our object "human action and behaviour" in a way that it complies with recent results in neuroscience? Human action and behaviour are determined by human abilities which are integrated abilities. On the basis of the coevolution of "genes, mind, and culture" human abilities can be considered to be rooted in human nature and to be influenced by the environment and culture. Coevolution tells us that this influence not only occurs by learning but is already guided by the genes by what is called "prepared learning" [Seligman 1970], [Wilson 2004, 65]. Prepared learning determines our view of the world or what we are able to learn at all and as a result affects the genetic basis. Lumsden \& Wilson even speak of "culturgens" [Lumsden \& Wilson 2005, Ixvi]. The thesis of the interaction or "symbiosis between brain and culture" is, for instance, also supported by Merlin Donald [Donald 1991, 2001].

In order to detect how competence-in-performance works, we need a key concept to open up the complex. What can count as the leading force in human beings' actions and behaviour? From an evolutionary point of view human beings are purposive beings by their very nature. It is human interests, needs and desires which determine their action and behaviour. Human needs are on the one hand needs to know, on the other hand needs to coordinate and direct actions of others. With respect to survival needs, human beings want to act successfully. By identifying an ability of rationality-in-performance we presuppose purposive action guided by reason but open to chance and individual decisions. Rationality-in-performance as a human ability needs to comply with the interaction of human nature, culture and the natural environment. I can only mention a few essential features in this regard; for a more detailed description you are referred to my recent books [Weigand 2010, 2009a].

Let us start with features rooted in human nature:

- Human abilities are integrated abilities.

- Human beings are purposive beings.

- Human beings are social individuals; their action and behaviour are determined by a double interest: self-interest and social concerns. 
- Human beings are persuasive beings; they want to be accepted by their fellow beings.

Persuasion is usually conceived of as belonging to rhetoric, cf., e.g., [Perelman 1977]. To consider human beings as persuasive beings means giving up the traditional distinction between purely rational or necessary conditions and argumentative or acceptable conditions, a distinction which in the end relates to the distinction between absolute truth and truth from the perspective of the speaker. Rhetoric claims to describe effective language use, i.e., persuasive language use. What can count as effective or persuasive interaction depends on individual evaluation. Persuasion is a mental perlocutionary process; in the end, only the dialogue partners can tell us whether they have been "persuaded". Consequently, effectiveness is not completely calculable nor is it rationally or conventionally achievable. Speakers try to be effective by means of rhetorical strategies. Rhetoric in this sense is a matter of how to use the means in performance, including what arguments to choose, i.e., a matter of the speakers, not a matter of textual means as such.

Human nature is from the very outset influenced by the environment. Occasions and events change as time changes. Human beings need to adapt to ever-varying action conditions. Their ability of rationality-in-performance tells them how to proceed: they first orient themselves according to regularities. If they cannot obtain a satisfying picture, they include particularities and make individual inferences. In this way they are prepared to meet chance and to change direction on the basis of principles of probability. They start from standard cases based on rules and conventions and proceed to particular cases by including individual, non-conventional features. Their way of addressing complexity is a way determined by rationality-in-performance:

- Human beings adapt themselves to the ever-changing environment.

- Human beings start from standard cases and proceed to particular ones.

- Human beings derive subsystems by specialization.

To illustrate this procedure let us imagine that we are involved in complex interactions, for instance, business interactions. We cannot clearly see what is really going on because we cannot grasp all the relevant variables at once. What are we doing? We pay attention to what seems especially crucial. We tentatively identify some regular case. If this does not fit actual performance, we advance by tentatively bringing in particular, individual features and try to reach understanding by inferences. There is no other way of orientation in a world of uncertainties than on the basis of probabilities.

The third force which affects human action and behaviour is, of course, culture. On the one hand, culture is manifest in the external environment as customs and value systems. On the other hand, it has been internalized as "culturgens". Accepting the basis, we can derive the following basic feature which affects human action and behaviour mostly unconsciously [Weigand 2007]:

- Human beings are cultural beings. 


\subsection{Deriving methodology from the object}

Having grasped our object competence-in-performance, of which rationalityin-performance is an integrated crucial component, we can now derive methodology from the object and in this way develop a theory of performance.

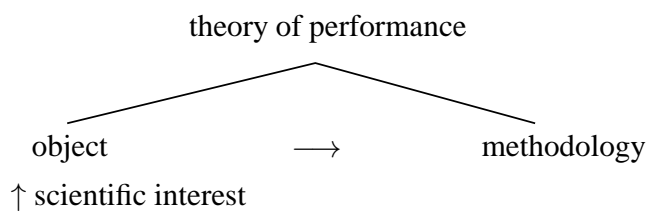

Figure 1: Constituents of a theory

In general, a theory is based on an object-of-study and an adequate methodology. An object of performance which includes rules as well as individualities and chance can only be dealt with by principles of probability. Even rules are subject to probability insofar as it is the individual human being who decides whether to apply them or not.

Principles of probability do not mean "axiomatic principles" as Linell [Linell 2009, 11] and Rommetveit [Rommetveit 1990] use the term "dialogical principles" nor do they mean statistical probability. Statistics does not allow certain conclusions about the individual case. Principles of probability, on the contrary, are techniques which allow human beings to estimate the individual course of events with a certain degree of probability by reference to everyday experience and special knowledge of the individual case.

When confronted with the complex, we are not the victims of chaos but are able to master it. Endowed with rationality-in-performance we have an extraordinary ability at our disposal, which is as simple as it is effective: we focus attention on some subcomplex because the whole complex is beyond our reach. We then proceed from standard cases based on regularities to particular ones by taking account of individual features.

Regularities are of different kinds: they can be causal rules as in natural sciences or coded rules as in structural linguistics; they can also be conventions of use. Rules are features of the object, independent of the user, whereas conventions are dependent on user groups. Conventions can become norms if they are considered the proper manner of behaviour we should conform to. In contrast to conventions, norms cannot count as communicative means. There are, for instance, conventions of so-called "civilized behaviour", such as avoiding insinuations, which are expected in public or institutionalized games. The interlocutors are, in principle, free to conform to them. Their behaviour can however be evaluated by observers according to normative benchmarks (for an authentic example see [Weigand 2008, 15]). Norms are thus a culturally dependent benchmark of behaviour which are to be included in the description 
without changing the descriptive theory to a normative one. Even strictly grammatical norms might be disregarded by the user as is, for instance, the case in chat communication. In the end, it is always individual human beings who decide whether to conform to norms or not.

I will demonstrate by a few introductory examples how principles of probability can be rationally derived from the premises about the object. Rational derivation in this respect means that the object is characterized by certain features which determine the way it works. I need to restrict myself to the procedure in general. Basically, there are three types of principles: constitutive, regulative and executive ones. Constitutive principles are principles that constitute dialogic action in its fundamentals. Constitutive in this sense are the principles of action, of dialogue and of coherence. Regulative principles come to work on the basis of constitutive principles. They regulate the interaction of subsystems which can turn out to be in opposition to each other. Regulative are the principles of politeness versus self-interest and of reason versus emotion. Reason is always more or less affected by emotion as has finally been proved by neuroscience. Executive principles guide the dynamics of the dialogic process. The principles of sequencing and of strategic use are executive. Strategies of successful action depend on cultural conventions and on certain ideologies in the background. The Maxim of Clarity, introduced by Grice, might be successful in science but is certainly not a general strategy of language use [Grice 1975].

Let us start with the Action Principle. If human beings are goal-directed beings, the theory needs an action-theoretic basis:

goals and purposes as driving force $\rightarrow$ Action Principle

Figure 2: Deriving the Action Principle

If human beings are social individuals, their communicative actions will always be dialogically oriented, either as initiative actions which make a dialogic claim or as reactions which are expected to fulfil this very claim:

human beings as social individuals $\rightarrow$ Dialogic Principle proper

Figure 3: Deriving the Dialogic Principle proper

From the premise that human abilities are integrated abilities or abilities in interaction, the conclusion to be drawn is that there is no such thing as language as such. The ability to speak interacts with other abilities. Consequently, coherence can no longer be a matter of the verbal text alone but is ultimately established in the minds of the interlocutors:

The Principle of Coherence is crucial for the use of different communicative means. If human beings are persuasive beings, any communicative means they 


$\begin{aligned} \text { interaction of abilities } \rightarrow \quad & \text { Coherence Principle: } \\ & \text { verbal, perceptual, cognitive means in } \\ & \text { integration }\end{aligned}$

Figure 4: Deriving the Principle of Coherence

use will in the end be used in order to be accepted by the community or to be more or less successful in their affairs. Consequently, rhetoric can no longer be a separate domain in describing performance; any means, any technique and strategy is used more or less persuasively:

human beings as $\rightarrow$ dialogic means as rhetorical means in general persuasive beings no separation between grammar and rhetoric

Figure 5: Consequences for rhetoric

Constitutive principles are accompanied by regulative and executive principles which are also derived from the premises. If human beings are social individuals, they have to regulate their self-interest and social concerns by means of principles of politeness. Politeness can mean respect for the other human being or can be used in the self-interest of the speaker in order to make things easier:

$\begin{array}{ll}\begin{array}{l}\text { human beings as social } \\ \text { individuals }\end{array} & \rightarrow \begin{array}{l}\text { Regulative Principles } \\ \text { of Politeness }\end{array}\end{array}$

Figure 6: Regulating self-interest and social concerns

When human abilities interact, regulative principles are also needed to mediate between abilities which may turn out to be in opposition to each other, such as reason and emotion. Principles of Emotion mostly represent cultural expectations or conventions and are often expressed as normative maxims which tell us how to deal with emotions in dialogue:

human abilities as integrated $\rightarrow \quad \begin{aligned} & \text { Regulative Principles } \\ & \text { of Emotion }\end{aligned}$
abilities

Figure 7: Regulating emotion and reason

If human beings are cultural beings, culture can no longer be an additional component but will be basic everywhere in human action and behaviour. Culture is manifest from the very beginning in shaping the image of the individual human beings and their relationship to the community. Regulative Principles of politeness and emotion are therefore in general culturally shaped: 


$$
\begin{aligned}
& \text { human beings as cultural beings } \rightarrow \quad \text { culturally shaped } \\
& \text { Regulative Principles }
\end{aligned}
$$

Figure 8: The influence of culture

If human beings are goal-directed beings, they need principles of how to proceed in complex dialogues or of how to execute the sequencing of actions in order to be successful. Such Executive Principles guide the follow-up of actions and reactions in extended dialogues:

$$
\begin{array}{ll}
\text { human beings as } \\
\text { goal-directed beings }
\end{array} \rightarrow \begin{aligned}
& \text { Executive Principles } \\
& \text { in extended dialogue }
\end{aligned}
$$

Figure 9: Strategic Principles

Executive Principles can take the form of strategies which are clearly directed towards effective language use or towards being successful in the process of negotiation.

\section{From rationality of logic to rationality-in- life}

Having sketched some overall conclusions which can be rationally drawn from the premises and which elucidate how human beings proceed in dialogic interaction on the basis of our competence-in-performance, let us now try to clarify more precisely what rationality-in-performance means and how it can be differentiated.

Rationality is not an object but characterizes a conclusion. Conclusions have a starting point and follow certain criteria in order to arrive at the intended result. The starting point and the criteria can be very different depending on different concepts of conclusion. To my mind, there are, on the one hand, criteria which are independent of the situation of use and, on the other hand, criteria dependent on use. Independent criteria constitute artificial systems, criteria dependent on use constitute natural phenomena. Even if artificial systems are created by human beings in an attempt to bring order in natural disorder, their functioning is independent of human beings. The artificial system, for instance, of classical mathematics or chess, is object and methodology at the same time. As artificial systems they do not relate to reality at all. If we take the laws of physics as eternal laws, they are not the laws of nature. If we take the rules of logic or chess as rules of language games, we are dealing with artificial games. As soon as we try to find the proper laws 
of nature or of language use, we have to acknowledge the basic rule of performance which is a rule of probability. The change from certainty to probability has brought about the change from classical physics to quantum physics. We should however be aware of the fact that even quantum physics remains a physics within the limits of human cognition, despite different comments by influential physicists like Hawking, e.g., [Hawking 1988, 193].

Recognizing that performance is based on probability does not mean that we can do nothing else than guessing. Probability of life does not mean that we can only rely on statistical probability and thus remain in ignorance about our individual case. Human beings want a guideline for their own individual action. Rationality in life is based on reasonable expectancy in the individual case.

We can thus distinguish between rationality of artificial systems and rationality-in-life:

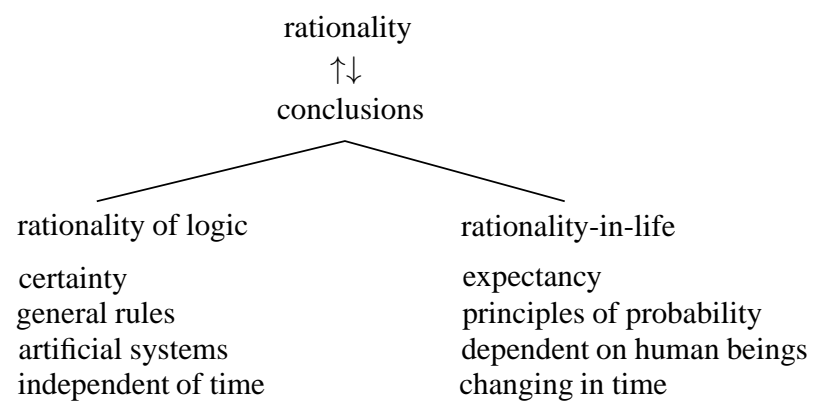

Figure 10: Certainty of logic versus expectancy in life

This two-part distinction between logic and life, between general rules and individual expectancy needs to be differentiated in order to include the area of conventions. Conventions are not general in the sense of independent rules insofar as they are introduced by and valid for certain groups, nations, or cultures. Theories of competence deal with conventions as they deal with rules, i.e., on a general basis, independent of individual decisions. Conventions, in this sense, only allow us to choose between general, predetermined possibilities [Lewis 1969]. Pragmatic theories introduced the concept of individuality, mostly however inconsistently by adding together two systems, the system of signs and the system of inferences, which are incompatible with each other. Coherence in individual language use does not come about by adding together two systems but is established by the interlocutors in their minds. Rationalityin-performance is not an ability of a system but a human ability. Human beings apply rules and conventions as far as they seem appropriate or acceptable to them. In this sense, rules and conventions in performance are dependent on probability decisions by individuals. 
There are obviously different degrees of probability, ranging from high to low. We can expect with high probability that speakers comply with the grammatical rules of their mother tongue, with less probability that they comply with cultural conventions, for instance, conventions of civilized behaviour. Cases of low probability are based on individual conclusions in particular games and are open to misunderstanding. Including individuality does not mean guessing or trial and error. It is guided by expectancy based on the knowledge of particularities of the individual case.

Probability concepts such as habits and preferences play an important role in human competence-in-performance. They are very often the key to rationality in performance. We have certain assumptions about the preferences of our interlocutors which affect our conclusions even if we are not aware of them. Preferences are by their very nature valid in the majority of cases, but not in all cases. They therefore cannot be predicted with certainty. The same is true of the concept of habits. We take certain habits for granted, but habits like preferences can change in particular cases. We can distinguish between conventional habits and preferences of social communities and nonconventional habits and preferences of individual human beings. The scope of rationality concepts as applied in different models thus ranges from strict rationality of logic to individual rationality-of-performance:

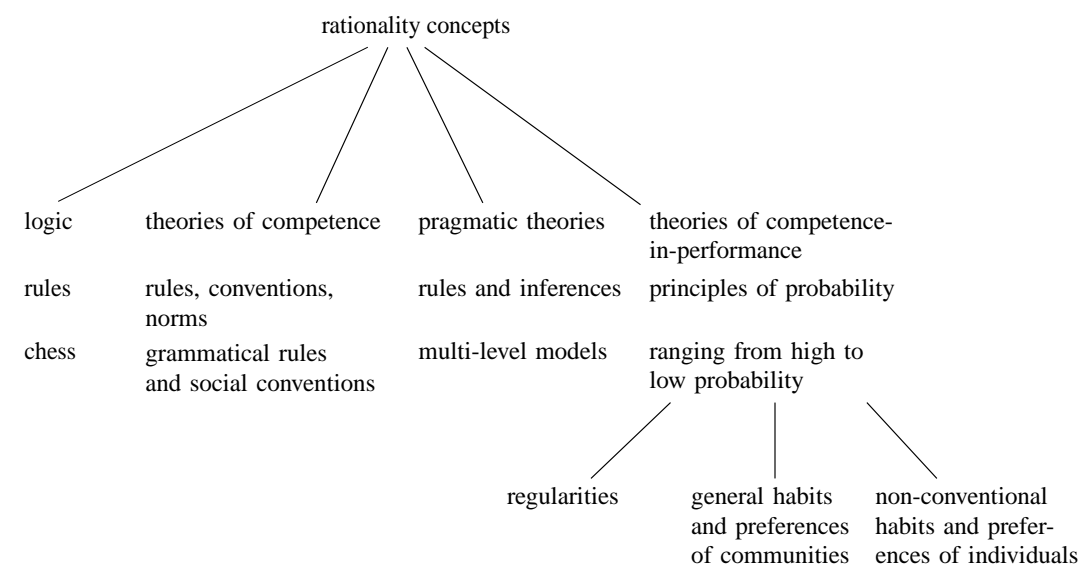

Figure 11: Types of rationality

Logic and theories of competence do not include individuality. Pragmatic theories, as far as they are based on the adding together of different methodologies, rest on an inconsistent basis. Consistency is achieved by starting from the human mind and from the integration of human abilities as included in the Principle of Coherence in a theory of competence-in-performance. 


\section{Examples of rationality in performance}

Let us now analyse a few examples which demonstrate how human beings as cultural, dialogic and adaptive beings meet the challenge of performance by rationality-in-performance. Rationality-in-performance or practical reason is an integrated part of our actions and behaviour insofar as human beings as purposive beings try to achieve their goals more or less successfully. The analysis focuses on how the Principle of Coherence works. This can also be interesting for Artificial Intelligence and the issue of how far computers could possibly tackle indeterminacy of meaning and reference to common and individual habits.

\subsection{Rationality of high probability}

Let me start with examples which demonstrate rational conclusions of high probability:

(1) It's draughty. - I'll close the window.

The predication that it is draughty inherently carries a negative evaluation, at least in normal circumstances. With high probability it will trigger off a reaction as in our example. If we mark the lexical items as $[ \pm$ positive], the conclusion should be possible also for computers: Of course, even conclusions

$$
\text { draughty }_{\text {negative }} \rightarrow \text { BRING TO AN END }
$$

Figure 12: Inherent conclusiveness

of inherent conclusiveness will, in principle, remain open under conditions of performance.

\subsection{Rationality of general habits}

Let us now focus on a very interesting case which demonstrates how language use and general habits of life or preferences are entwined. I will take the well-known example from Brown and Yule [Brown \& Yule 1983]

The doorbell is ringing. - I'm in the bath.

The occurrence that "the doorbell is ringing" usually means that someone is standing at the door and wants the door to be opened. In the same way "being in the bath" is connected with the habit of not being prepared to appear in public. These habits need not be expressed explicitly; we rely on our mutual knowledge of habits in our social community. In this way, we usually mean more than we say by means of the integrated use of different communicative 
means: speaking and thinking. What is true for the individual utterances, the initiative as well as the reactive, is also true for their connection in the sequence: we need not resign by assuming a "zero connector" [Stati 1994], but can very precisely indicate how they are connected, namely by the Dialogical Principle proper, which determines the reactive action as an action that can be expected through the initiative claim, in our case the indirect claim to open the door: "If I am in the bathroom I am not prepared to open the door." It is the rational structure of the initiative speech act which determines what reaction is expected.

What I called reference to habits is usually dealt with as encyclopaedic knowledge or knowledge of the world and added as a separate component to the verbal component. Yet what is world knowledge? It is what we believe to know of and think about the world. Language is used "in the stream of life" [Wittgenstein 1981], i.e., on the basis of what we believe to know about everyday habits. There is no independent world knowledge, no need to list it by enumerating items of encyclopaedic knowledge as is, for instance, done by frame semantics.

Now let us see how we could formalize these conclusions based on general habits. Where do they start from? The pivot seems to be the lexicon. It is the lexical phrase to ring the doorbell that initiates the inference to "open the door", and it is the lexical phrase being in the bathroom that initiates the inference to "not being prepared to appear in public". If we could include these habits in the lexical description, it would be possible even for a machine to connect both utterances by "rational" probability conclusions and arrive at the conclusion that I am in the bathroom indirectly expresses a refusal to open the door. The lexicon entries could be represented as follows:

$\begin{array}{lll}\begin{array}{l}\text { ring } \\ \text { [ringing (doorbell)] } \\ \text { REASON }\end{array} & \begin{array}{l}\text { indirect } \\ \text { [open the door] } \\ \text { COAChroom }\end{array} & \begin{array}{l}\text { CONCLSION } \\ \text { [being (in the bathroom)] }\end{array} \\ \text { REASON } & \rightarrow & \begin{array}{l}\text { [unable to appear in public/ } \\ \text { unable to open the door] } \\ \text { CONCLUSION }\end{array}\end{array}$

Figure 13: The lexicon and its role in the process of inferencing

Coherence is thus achieved in the following rational way that brings negotiation down to patterns of probability (see Figure 14).

Rationality in this sense means practical reasoning based on probability and accepting a certain indeterminacy. If the lexical items which I consider to be phrases [Weigand 1998] are annotated in this way, i.e., indicate presumable relationships between events of human life, it will be possible even for machines to trigger off these sequences and make machines "think" along the lines of 


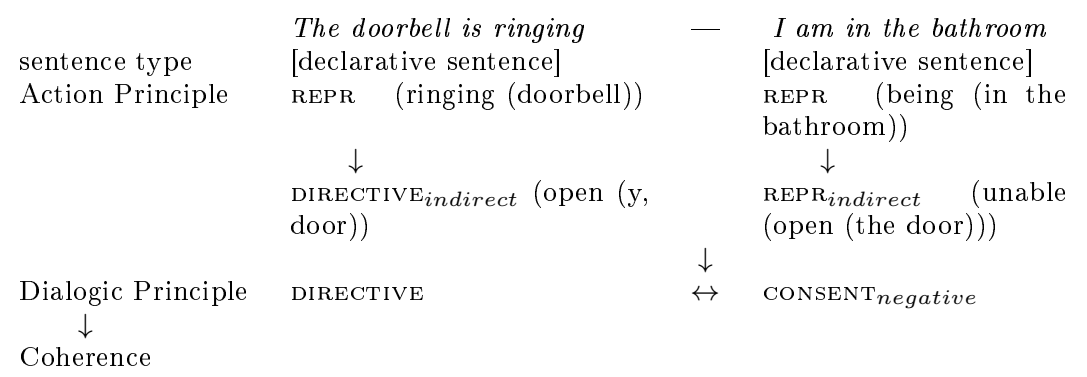

Figure 14: Coherence on the basis of probability

probability [Weigand 2009b]. It becomes evident that the lexicon cannot be dealt with as an independent part of utterance grammar. On the contrary, the lexicon turns out to be the crucial connecting point of predication and action.

What I demonstrated with respect to lexical units such as ringing the doorbell or being in the bathroom is also true of many other lexical units such as to wait, being late, etc., as can be seen in the following examples which are very similar to example (2):

(4) Doris is waiting at the airport. - I'll fetch her.

Examples like these demonstrate that indirect speech acts very often bear on their lexical items even if the conclusion to be drawn from the use of the lexical item is left to the interlocutor. The issue of the lexicon should therefore be completely revised. Probability concepts such as habits, preferences and evaluations enter the lexicon if it is conceived of as an integrated part of a dialogic utterance grammar.

In contrast to such a conception of the lexicon which goes beyond fixed patterns, formal semantics, e.g., Pustejovsky [Pustejovsky 1995] or Mel'čuk \& Wanner [Mel'čuk \& Wanner 1994], start from the premise that the meaning of words can be described in a completely rule-governed way and that units of more than one word can be derived from the meaning of individual words. But in doing so Mel'čuk and Wanner are clearly aware of the fact that they can only describe a small part of the vocabulary using such a rule-governed technique. While Pustejovsky does not acknowledge the methodological fallacy he is a victim of, Mel'čuk and Wanner finally recognize that the "capricious" nature of natural language cannot be grasped using a rule-governed model. If we look for an algorithm we arrive at a point where we have to admit like Teubert: "Something must be wrong, however" [Teubert 1996, 225] and where we necessarily come to the conclusion: "It may well be that we will have to recognize that there are neither obvious regularities nor applicable rules." 
The difficulties formal approaches run into if they do not accept probability conditions demonstrate once again that we, unlike Sinclair [Sinclair 1994], cannot "trust the text" because the verbal text is only a component in the mixed game. Human beings are adaptive beings who normally do not make a distinction between text and context, between acting and interpreting, but interact in the action game by integratively accounting for variables of different types. They cannot proceed otherwise even if they wanted to.

\subsection{Rationality of low probability}

Let us now analyse an example of rationality of low probability. Such examples are often the source of misunderstandings because they bear on the uncertainty of actual habits and preferences. Typical examples of this type are the following authentic examples:

You are playing the piano again.

You are playing Game Boy again.

How to deal with the meaning of such utterances in Artificial Intelligence? Obviously certain declarative sentences can imply positive or negative evaluations and in dependence trigger off certain reactions. The conclusions to be drawn from what is said to what is meant need to take account of individual preferences.

In our examples a statement is made verbally, no evaluation is expressed. At least for example (6) or for playing Game Boy, there is no generally agreed upon cultural evaluation. Some parents might be pleased to see their child engaged in what they consider an intellectual activity, others might be annoyed by what seems to have become a never-ending activity. For example (5) or for playing the piano, we could assume a positive cultural evaluation which however does not have to be valid in the actual case. The interlocutor, who is playing the piano, tries to make sense of the utterance first by applying rules: the utterance is a declarative sentence, in the indicative present tense, therefore a speech act of a statement. But why is this statement made? Why has attention been focused on my playing the piano? In some cases, intonation is a valid device; in other cases, however, it does not provide a clear cue. In our authentic example, the intonation is not distinctive in expressing whether the statement is accompanied by satisfaction or anger. So far the rules have come to their limits. The interlocutor has to adapt to the particular situation and to look for individual features. What has been said and what can be perceived, for instance, the facial expression of the speaker, has to be combined with cognitive means or inferences which depend on knowledge of the particular situation. Even if the interlocutors know each other well, there will always remain a certain leeway of uncertainty due to chance and the actual mood of the speaker. As there is no verbal context, in the end, only the speaker can know with certainty how the utterance is meant. 
Human beings do not immediately give up in such cases but go beyond rules and try to find some guideline by reflecting on what probably is the case. Thus the child playing the piano might know that her mother at the time of the utterance is usually involved in work connected with her job and needs silence. She will therefore probably take the utterance you are playing the piano again as a reproach:

(7) A. You are playing the piano again.

B. Shall I stop it?

A. No, it is o.k. I am going to work outside.

In adapting to the complex she starts with her mother's habitual preference which - being a concept of probability - is not a secure guide and, in our case, leads to misunderstanding. Misunderstandings can be accepted as they are usually corrected immediately as in our example.

To sum up: The examples analysed demonstrate the complex balance of parameters in performance and how this balance can be managed by rationality-in-performance. Human performance is dialogic performance based on the relation of expectancy between action and reaction as expressed by the general Dialogic Principle proper. Expectancy primarily draws on the rational structure of the initiative speech act. With the initiative action the speaker makes a pragmatic claim to truth or to volition and can expect that their very claim is fulfilled by the interlocutor's reaction, positively or negatively. By rationally differentiating the pragmatic claim of the initiative speech act a comprehensive dialogic speech act taxonomy can be derived. Whereas the Dialogic Principle proper regulates the functional sequence of actions, the Coherence Principle is constitutive for the correlation between what is said and what is meant.

To my mind, even computers could be programmed in such a way as to be capable of tackling the balance of probabilities in performance, at least to some extent. However, we have to leave behind us orthodox concepts of signs and defined meaning and start from larger units, primarily the dialogically oriented utterance.

\section{Outlook}

If we want to grasp rationality-in-performance we need to go beyond classical concepts of strict rationality and address the integrated whole of human action and behaviour. There is no language as such, no cognition or perception as such, there are human beings who act and react as dialogic individuals. They have needs and interests and are endowed with extraordinary abilities which allow them to come to grips with the vicissitudes of life. 
If science is to contribute to the benefit of the human species, we need to go beyond disciplinary boundaries and dare the adventure of a holistic approach. "Les lois du chaos" are not general or autonomous rules, but rules which mediate between order and disorder, between the general and the particular. Progress in science cannot be set back. We are on the way towards the unity of knowledge or consilience of different disciplines, from the natural sciences to the social sciences and the humanities. It is human beings, their biology and social abilities, which have to be investigated in an integrated manner. We need to free ourselves from methodological exigencies of the past, inherited since antiquity. Theorizing needs to be changed from classical theorizing based on reductionism to modern theorizing based on the rationality of the complex whole.

\section{Bibliography}

Barkow, Jerome H., Cosmides, Lea, \& Tooby, John (eds.) [1992], The Adapted Mind: Evolutionary psychology and the generation of culture, New York: Oxford University Press.

Brown, Gillian \& Yule, George [1983], Discourse Analysis, Cambridge: Cambridge University Press.

Damasio, Antonio [1994], Descartes' Error. Emotion, reason, and the human brain, New York: Putnam.

[2000], The Feeling of What Happens. Body, emotion and the making of consciousness, London: Vintage.

Donald, Merlin [1991], Origins of the Modern Mind: Three stages in the evolution of culture and cognition, Cambridge, MA: Harvard University Press.

[2001], A Mind So Rare: The evolution of human consciousness, New York: Norton.

Einstein, Albert [1922], Sidelights on Relativity, London: Methuen.

Ellis, Nick C. \& Larsen-Freeman, Diane (eds.) [2010], Language as a Complex Adaptive System, Oxford: Wiley-Blackwell.

Feynman, Richard P. [2001], The Pleasure of Finding Things Out, London: Penguin Books.

Gell-Mann, Murray [1994], The Quark and the Jaguar. Adventures in the simple and the complex, London: Abacus. 
Grice, Paul H. [1975], Logic and conversation, in: Syntax and Semantics, edited by P. Cole \& J. L. Morgan, New York: Academic Press, vol. 3, 4158.

Hauser, Marc D., Chomsky, Noam, \& Fitch, W. Tecumseh [2002], The faculty of language: What is it, who has it, and how did it evolve?, Science, 298(5598), 1569-1579.

Hawking, S. [1988], A Brief History of Time. From the Big Bang to Black Holes, Toronto: Bantam Books.

Iacoboni, Marco [2008], Mirroring People. The New Science of how we connect with others, New York: Straus \& Giroux.

Kendon, Adam [1980], Gesticulation and speech: Two aspects of the process of utterance, in: The Relationship of Verbal and Nonverbal Communication, edited by M. R. Key, The Hague: Mouton, 207-227.

Lewis, D. [1969], Convention: A philosophical study, Cambridge: Harvard University Press.

Linell, P. [2009], Rethinking Language, Mind, and World Dialogically. Interactional and contextual theories of human sense-making, Charlotte, NC: IAP-Information Age Publishing.

Lumsden, C. J. \& Wilson, E. O. [2005], Genes, Mind, and Culture: The coevolutionary process, New Jersey: World Scientific.

MCNeIll, David [2005], Gesture and Thought, Chicago: The University of Chicago Press.

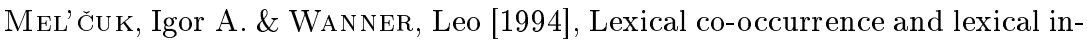
heritance. Emotion lexemes in German: A lexicographic case study, Lexikos, 4, 86-161, Afrilex-Reeks/Series 4, Stellenbosch/Republik Südafrika.

Mercier, Hugo \& Sperber, Dan [2011], Argumentation: Its adaptiveness and efficiency, Behavioral and Brain Sciences, 34(2), 94-111.

Perelman, Chaïm [1977], L'Empire rhétorique. Rhétorique et argumentation, Paris: Vrin.

Prigogine, Ilya [1994], Les Lois du chaos, Paris: Flammarion.

Pustejovsky, James [1995], The Generative Lexicon, Cambridge, MA: The MIT Press.

Rizzolatti, Giacomo \& Arbib, Michael A. [1998], Language within our grasp, Trends in Neurosciences, 21(5), 188-194. 
Rommetveit, Ragnar [1990], On axiomatic features of a dialogical approach to language and mind, in: The Dynamics of Dialogue, edited by I. Marková \& K. Foppa, New York: Harvester Wheatsheaf, 83-104.

Searle, John R. [2001], Rationality in Action, Cambridge, MA; London: The MIT Press.

Seligman, Martin E. P. [1970], On the generality of the laws of learning, Psychological Review, 77, 406-418.

Simon, Herbert A. [1962], The architecture of complexity: Hierarchic systems, in: Proceedings of the American Philosophical Society, vol. 106, 467-482.

— [1983], Reason in Human Affairs, Stanford: Stanford University Press.

Sinclair, John [1994], Trust the text, in: Advances in Written Text Analysis, edited by M. Coulthard, London; New York: Routledge, 12-25.

Stati, Sorin [1994], Formal devices for connecting argumentative moves, in: Text und Grammatik. Festschrift für Roland Harweg zum 60. Geburtstag, edited by P. Canisius, C.-P. Herbermann, \& G. Tschauder, Bochum: Brockmeyer, 52-61.

Teubert, Wolfgang [1996], Comparable or parallel corpora?, International Journal of Lexicography, 9(3), 238-264.

Toulmin, Stephen [2001], Return to Reason, Cambridge, MA; London: Harvard University Press.

Trognon, Alain [2013], Pragmatics re-established on its feet: Weigand's Mixed Game Model 2010, Language and Dialogue, 3(3), 457-476.

Weigand, Edda [1998], Contrastive lexical semantics, in: Contrastive Lexical Semantics, edited by E. Weigand, Amsterdam; Philadelphia: Benjamins, $25-44$.

— [2007], The sociobiology of language, in: Dialogue and Culture, edited by M. Grein \& E. Weigand, Amsterdam; Philadelphia: Benjamins, 27-50.

[2008], Rhetoric in the Mixed Game, in: Dialogue and Rhetoric, edited by E. Weigand, Amsterdam; Philadelphia: Benjamins, 3-24.

[2009a], Language as Dialogue. From rules to principles of probability, Amsterdam; Philadelphia: Benjamins.

[2009b], Patterns and beyond in lexical semantics. The issue of word meaning in language technology, in: Language as Dialogue. From rules to principles of probability, edited by S. Feller, Amsterdam; Philadelphia: Benjamins, 219-239. 
— [2010], Dialogue: The mixed game, Amsterdam; Philadelphia: Benjamins.

Wilson, Edward O. [2004], On Human Nature. With a new preface, Cambridge, MA; London: Harvard University Press, (originally published in 1978).

Wittgenstein, Ludwig [1981], Zettel, Oxford: Blackwell, 2nd edn., 1967. 